Article

\title{
Institutional Change and the Implementation of the Ecosystem Approach: A Case Study of HELCOM and the Baltic Sea Action Plan (BSAP)
}

\author{
Savitri Jetoo* and Nina Tynkkynen (D) \\ Faculty of Social Sciences, Business and Economics, Åbo Akademi University, Tuomiokirkontori 3, \\ 20500 Turku, Finland; nina.tynkkynen@abo.fi \\ * Correspondence: savitri.jetoo@abo.fi
}

check for updates

Citation: Jetoo, S.; Tynkkynen, N. Institutional Change and the Implementation of the Ecosystem Approach: A Case Study of HELCOM and the Baltic Sea Action Plan (BSAP). Environments 2021, 8, 83. https:// doi.org/10.3390/environments 8080083

Academic Editor: Zacharias Frontistis

Received: 30 June 2021

Accepted: 18 August 2021

Published: 19 August 2021

Publisher's Note: MDPI stays neutral with regard to jurisdictional claims in published maps and institutional affiliations.

Copyright: (c) 2021 by the authors. Licensee MDPI, Basel, Switzerland. This article is an open access article distributed under the terms and conditions of the Creative Commons Attribution (CC BY) license (https:// creativecommons.org/licenses/by/ $4.0 /)$.
Abstract: The goal of this article is to explore the ways in which institutional changes are made to accommodate the application of the ecosystem approach for the governance of international environmental organizations. It examines the case of the Helsinki Commission, the governing body for restoration of good ecological status to the Baltic Sea, using the Baltic Sea Action Plan (BSAP) as its main tool. The Parties to the Helsinki Convention committed to adopting the ecosystem approach in the BSAP, recognizing that a clear shift was needed from the previous sectoral emphasis. The analysis is relevant and timely, as a review of BSAP indicates that implementation actions are lagging. The findings show that while the ecosystem approach influenced problem framing and envisioning, the overarching governance paradigm within HELCOM has not changed. Targeted transition leadership is crucial to guide more formal rules of engagement among actors and sectors for the better implementation of this holistic approach.

Keywords: institutional change; ecosystem approach; transition management; governance; Baltic Sea; Baltic Sea Action Plan; Convention on Biological Diversity

\section{Introduction}

In recent years, environmental governance has experienced a paradigm shift resulting from the emergence and diffusion of the so-called ecosystem approach, which has become the guiding principle to achieve and maintain good environmental status. This approach addresses the interactions within an ecosystem and between the ecosystem and society, as well as the impacts of management beyond the boundaries of a single sector, implying a shift from sectoral management to multi-sectoral and holistic approaches [1]. Many open questions remain relating to how the ecosystem approach is realized in environmental governance, international environmental organizations included. These organizations have adopted the approach and it can be assumed that the institutions have changed accordingly, as the adoption of the approach necessitates certain institutional changes. This paper examines the governance demands of the ecosystem approach in international environmental organizations with the Helsinki Commission (HELCOM) as the case study.

HELCOM is the governing body of the Convention for the protection of the Marine Environment of the Baltic Sea Area (more commonly called the Helsinki Convention), signed in 1974 [2]. Whilst the original Helsinki Convention focused on sectoral pollution prevention and was developed during a period of diplomacy between the coastal countries, the Convention and the HELCOM have since undergone changes. The Convention has expanded to include membership of the European Union, Russia as a successor of the USSR, as well as the newly independent Baltic States in 1992. HELCOM changed its structure and instruments to aid implementation efforts. One such instrument is the Baltic Sea Action Plan (BSAP) that was adopted by member states in 2007, with the aim of implementing the ecosystem approach to achieve good ecological status of the Baltic Sea by 2021. The BSAP 
focused on four strategic goals reflecting the desired status of the Baltic Sea: (i) Baltic Sea unaffected by eutrophication; (ii) Baltic Sea with life undisturbed by hazardous substances; (iii) maritime activities carried out in an environmentally friendly way; leading to (iv) the favourable conservation status of Baltic Sea biodiversity [3]. BSAP acknowledges that the ecosystem approach is based on the integrated management of human activities and the ecosystem, taking into account the impact and actions for improving the ecosystem [1,4-6].

Whilst HELCOM was previously focused on sectoral governance, e.g., division into discrete policy sectors such as shipping etc., a clear shift was required for a more integrated systems approach for European marine governance. The holistic ecosystem approach is critical to the governance of the complex socio-ecological interactions of challenges facing European marine environments, where sectoral and fragmented measures fall short. However, successful implementation entails an improved understanding of the approach within disciplines, institutions and stakeholders [7].

Changes in governance were needed to enable closer cooperation and integration of policy sectors and different actors to facilitate the ecosystem approach. This was a welcome change from the traditional hierarchical relational underpinnings of most of the Baltic Sea governance networks [8]. The responsibility for the implementation of the BSAP lies at the member state level. The establishment of National Implementation Programmes by each HELCOM member state, mostly from 2010, was the first step for following up on the progress of implementation actions [9]. Since 2016, such progress can also be followed through a HELCOM Explorer online database.

The structure of the BSAP into four strategic goals reflects the joint major environmental problems of the Baltic Sea. Was this ambition accompanied by institutional changes within HELCOM, including transformations in both informal and formal rules and public engagement? This question is especially relevant as the governance of transformation is often underdeveloped and needs greater attention [10]. Furthermore, research has found that the ecosystem approach has the potential to improve HELCOM's adaptive capacity [11]. In the case of HELCOM, the analysis of the institutional change following the efforts to apply the ecosystem approach is especially pertinent at a time when review of the BSAP implementation indicates that implementation actions are lagging behind the desired status $[12,13]$. It is also relevant as it can inform the dialogue on the update of the BSAP that will be announced in 2021.

To examine the governance demands of the ecosystem approach, this paper uses the transition management framework $[14,15]$ to analyse the institutional changes of HELCOM in implementing this new governance approach in the BSAP. The paper proceeds as follows: the next section describes the theoretical framework consisting of transition management as well as identification of the governance requirements of the ecosystem approach and the analysis of BSAP vis-à-vis the ecosystem approach. Materials and methods then follow. Furthermore, the empirical findings regarding the institutional change are presented and discussed by using the transition management approach as an analytical lens, ending with a conclusion discussing the relevance of the study in a broader context.

\section{Theoretical Framework}

\subsection{Transition Management}

HELCOM is one of the main governing institutions of the Baltic Sea. Here, institutions refer to those rules, rights and decision-making procedures that give rise to social practices [15]. HELCOM sets these rules and decision-making procedures along with the parties to the Helsinki Convention for the implementation of the ecosystem approach. The literature shows a gap in how the ecosystem approach is applied in environmental governance resulting from poor understanding of the change process which encompasses many issues such as the values of society, adoption of new practices and institutional dynamics [15]. The latter is relevant to this paper, as it investigates the transformation of HELCOM for implementation of the ecosystem approach. This paper uses the transitions management approach to investigate the context in which changes were made by HEL- 
COM for the application of the ecosystem approach. The word transitions is used to refer to societal or subsystems transformations that fundamentally changes their structure [16], such as changes needed for implementation of the ecosystem approach. The literature has presented a number of approaches in addressing change in marine systems. Existing studies have considered single response variables to detect changes and have modelled cause effect dynamics in order to study drivers of change and their effects [17]. There are both problem- and process-focused tools for governing change, where problem-focused tools deliver outputs such as maps and process-focused tools are more about the processes of change $[11,18]$. The process-oriented transition management theory aims to move a system beyond a sector focus to more systemic, long-term changes. Developments from different scales from different domains positively reinforce each other during a transition [16] Transitions can be seen as the natural processes that allow for the concurrence of networks, institutions, markets, policies and society from one dynamic equilibrium to another.

Transition management has the potential to both conceptualize and effect strategies to address barriers to change based on a long-term perspective using a participatory process of visioning and experimentation ([15], p. 24). Transition management is a governance approach that connects science and policy in sectors such as transport, tourism, healthcare, land-use planning and water management $[14,15,19,20]$. It underscores the need for an integrated, system-wide perspective in dealing with wicked problems and as such, is a valuable tool for facilitating the institutional transformation highlighted by the principles of the ecosystem approach. Its strength lies in the potential to steer the direction and speed of the change dynamics in contributing to the end goals of the ecosystem approach, such as good ecological status. This approach was pioneered in 2001 in the Netherlands Fourth National Environmental Policy plan, in an attempt to "reinvigorate ecological modernisation" ([21], p. 78). Part of the appeal of this approach is its flexibility in relation to prevailing institutional commitments [21]. It sees complexity and uncertainty as opportunities to provide the launching ground for new ideas to be supported and streamlined.

The regime changes in the transition management approach have been conceptualised as a non-linear S curve, where the system reorganizes itself in the face of stressors to change into a higher order, more resilient state through four phases: the pre-development phase, take off, acceleration and stabilisation [22]. Novel practices emerge in the pre-development phase, which brings actors together in the take off phase to form common expectations and visions. These new practices gain momentum in the acceleration phase to gradually replace old ones in the stabilization phase where a new dynamic equilibrium is attained. There is a lot of experimentation but little noticeable change in the predevelopment phase, with shifts in the system taking place in the take off phase. Structural changes only become visible in the take acceleration phase through institutional, socio-cultural, economic and ecological changes that interact. In the acceleration phase there is also collective learning, diffusion and embedding processes. The speed of change decreases in the stabilization phase [16].

In reality, the transition management approach is a comprehensive, iterative and cyclical process. It aims to facilitate change through four intervention processes of orienting, agenda setting, activating and reflecting [23,24]. Orienting interventions are the initial actions aimed at exploring the transition challenge and setting baseline conditions. It includes setting up a transition team and building capacity for transitions. Agenda setting interventions build on this and aim to create a shared sense of ownership, integrating with different agendas and practices. This includes shared visioning for a different future. Activating takes this to the action implementation stage, where doing so includes pilot projects and shared learning. The final set of interventions, reflecting, include embedding a culture of reflexivity and learning by doing, in a culture that supports experimentation. This is explained in Table 1. 
Table 1. The transition management stages (after [23]).

\begin{tabular}{|c|c|}
\hline $\begin{array}{l}\text { I. Setting the scene for transition } \\
\text { management }\end{array}$ & $\begin{array}{l}\text { A transition team is formed to drive the process and embed } \\
\text { in the local context. }\end{array}$ \\
\hline II. Exploring local dynamics & $\begin{array}{l}\text { The transition team starts to explore the region's dynamics } \\
\text { conducting interviews and doing desk research and } \\
\text { working towards a system analysis and actor analysis. } \\
\text { Based on the actor analysis, a diverse group of change } \\
\text { agents is invited to engage in a series of meetings as a } \\
\text { transition arena group. }\end{array}$ \\
\hline $\begin{array}{l}\text { III. Framing the transition } \\
\text { challenge }\end{array}$ & $\begin{array}{l}\text { The change agents first explore the transition challenge and } \\
\text { create a shared problem framing. }\end{array}$ \\
\hline IV. Envisioning a sustainable city & $\begin{array}{l}\text { Subsequently, they exchange and elaborate perspectives on } \\
\text { a possible future, thereby creating visionary images for the } \\
\text { future of the Baltic Sea. }\end{array}$ \\
\hline $\begin{array}{l}\text { V. Reconnecting long term and } \\
\text { short term }\end{array}$ & $\begin{array}{l}\text { As a final step in the transition arena setting, the change } \\
\text { agents elaborate transition pathways, indicating } \\
\text { fundamental changes and corresponding actions needed to } \\
\text { reach the envisioned future. The ideas brought forward by } \\
\text { the transition arena are summarized and published in a } \\
\text { transition agenda. }\end{array}$ \\
\hline VI. Engaging and anchoring & $\begin{array}{l}\text { Actions are undertaken to make the transition agenda } \\
\text { public and give others a chance to adopt and adapt it and } \\
\text { relate it to their own agenda and practices. }\end{array}$ \\
\hline VII. Taking action & $\begin{array}{l}\text { Transition experiments, radical short-term actions in line } \\
\text { with the transition agenda, are initiated or adapted. } \\
\text { Through these actions, more actors become engaged. } \\
\text { Insights from these experiments can be taken to a more } \\
\text { strategic level. }\end{array}$ \\
\hline
\end{tabular}

\subsection{Governance Requirements of the Ecosystem Approach}

The ecosystem approach is a strategy for the integrated management of land, water and living resources that promotes conservation and sustainable use in an equitable way. It was the international community's response to the biodiversity crisis and is seen as the primary framework for achieving the main objectives of the Convention on Biological Diversity (CBD) [25]. It focuses on the processes of an organism and its environment in the ecosystem. "Ecosystem" means a dynamic complex of plant, animal and micro-organism communities and their non-living environment interacting as a functional unit (Article 2 of the Convention on Biological Diversity). As such, it means that governance can refer to any scale of analysis, from a grain of sand on the beach to the River Oder discharging nutrients into the Baltic Sea to the Baltic Sea itself.

The use of various terminology was acknowledged in the CBD (COP I, Decision IV/I1998) ([26], p. 56), which stated that whilst the ecosystem approach is addressed as the guiding principle, the varying terms have been used including the 'ecosystem approach', 'ecosystem process-oriented approach', 'ecosystem management approach' and 'ecosystembased approach. Although related, they are different groupings of terms, as the ecosystem approach-based terms have a governance and hence a strategic focus, whilst ecosystem management approaches are more operational, where the 'shovel hits the ground' actions materialise. According to Maltby [27], the ecosystem approach encompasses a long term vision with a working plan whilst ecosystem management changes with time and is judged in human terms. The ecosystem approach represents a holistic process to better integrate the biodiversity agenda [27] whereas ecosystem management represents a shift from living off nature's capital, to living off nature's interest ([28], p. 42).

As noted, the adaptive, ecosystem-based approach was explicitly stated in the BSAP and was based on the joint adoption of HELCOM and OSPAR Commissions [29] of the ecosystem approach as a new guiding concept, and the commitment to further develop 
and apply measures necessary to implement that approach by 2010 [4,13]. Accordingly, in the preamble to the BSAP, "the need for integrated management of human activities and the need to take into account their impacts on the marine environment in all policies and programmes implemented in the Baltic Sea region" was stressed ([3], p. 4). It further specified the "need for integration of environmental objectives with economic and socioeconomic goals in order to advance and strengthen the three interdependent pillars of sustainable development" ([3], p. 4). While these are welcome and highly relevant starting points for the application of the ecosystem approach in governance, they are by no means easy to accomplish and require institutional change, as will be demonstrated later in this paper.

The governance requirements of the ecosystem approach are very much linked to the core principles underlying the approach and have been addressed also in research related to the Baltic Sea governance [7,30-35]. The CBD has identified 12 core principles which will be discussed here in relation to the rules governing the use of the ecosystem approach, as well as to the recognition of the BSAP of these requirements [25].

Principle 1. The objectives of management of land, water and living resources are a matter of societal choice.

The BSAP recognises this principle by allowing flexible implementation of the ecosystem approach. Whilst targets are set for member states, the means of achieving these targets are flexible and allow tailoring to the purpose of regulations, organizational structures and negotiations among contested interests. This principle allows for and respects cultural and biological diversity.

Principle 2: Management should be decentralized to the lowest appropriate level; Principle 11: The ecosystem approach should consider all forms of relevant information, including scientific and indigenous and local knowledge, innovations and practices; and Principle 12: The ecosystem approach should involve all relevant sectors of society and scientific disciplines.

This follows from the principle above, which implies that all sources of knowledge should be included. This was not evident in most national implementation plans of the $\mathrm{BSAP}$, as the implementers were primarily national agencies [13].

Principle 3: Ecosystem managers should consider the effects (actual or potential) of their activities on adjacent and other ecosystems and Principle 9: Management must recognize that change is inevitable.

Management systems need to be designed to cope with time lags, non-linear interactions between ecosystems and the effects of decision making being spread beyond the point of impact. Whilst BSAP includes monitoring mechanisms, it does not comprehensively incorporate feedback mechanisms.

Principle 4: Recognizing potential gains from management, there is usually a need to understand and manage the ecosystem in an economic context.

This principle goes on to stipulate three conditions of the ecosystem-management programme:

(a) Reduce those market distortions that adversely affect biological diversity;

(b) Align incentives to promote biodiversity conservation and sustainable use;

(c) Internalize costs and benefits in the given ecosystem to the extent feasible.

This principle recognises that land-use changes represent the main threat to biological diversity. Ecosystems should be governed in an economic context, as economic structures undervalue or are unable to value ecosystems. As such, any institutional arrangement should incorporate the social and economic values of ecosystem goods and services in resource governance decisions. Many studies have noted that there has been a gap in governance of the BSAP to maximise the benefits of sustainability, as nutrient reduction targets, for instance, did not consider the individual country's economic reality [13,36-39].

Principles 5: Conservation of ecosystem structure and functioning, in order to maintain ecosystem services, should be a priority target of the ecosystem approach; and Principle 10: The ecosystem approach should seek the appropriate balance between, and integration of, conservation and use of biological diversity. 
The objective of governance decisions should be to maintain the resiliency of ecosystem structure and function. As such, management strategies should maintain and restore ecosystem structure and function. These strategies include managing protected area networks, and setting conservation, social and economic goals that guide policy using participatory inputs.

Principle 6: Ecosystems must be managed within the limits of their functioning.

This principle recognizes that the limits to the ecosystem functioning may be uncertain and, as such, adaptive governance mechanisms are needed. Institutions need to be designed in a flexible way to include a culture of continuous learning such that monitoring feedback loops can be incorporated into the system.

Principles 7: The ecosystem approach should be undertaken at the appropriate spatial and temporal scales and Principle 8: Recognizing the varying temporal scales and lageffects that characterize ecosystem processes, objectives for ecosystem management should be set for the long term.

The drivers affecting ecosystem resilience vary temporally and spatially, necessitating governance strategies that incorporate differing scales to achieve targets. When this is not taken into account, there can be a mismatch between the ecosystem time frames and that of management. For example, the target date for BSAP was set at 2021, whilst modeling shows it can take as long as 100 years to reach threshold values for dissolved inorganic nitrogen and phosphorus even after the targets in BSAP have been reached [12]. Spatial mismatches are also evident, as administrative boundaries allocated to nation states do not coincide with the properties of the Baltic Sea, where a more appropriate scale might be e.g., the Gulf of Finland.

In sum, these principles demonstrate that the ecosystem approach embraces adaptive governance, emphasising continuous learning as scientific monitoring information is fed back into the process, and changes made in operational procedures by management $[40,41]$. Drawing on this framework, this paper scrutinizes how well the HELCOM as an institution has been able to manage the transition towards the application of ecosystem approach when implementing the BSAP to meet the principles and governance requirements necessitated by the ecosystem approach. Was their adoption done through instant and wholesale governance changes, or have existing, unsustainable rules and practices persisted after the intent to adopt the ecosystem approach?

\section{Materials and Methods}

The research design is based on the transition management framework. The empirical data for this study were collected from two main sources: survey data and document analysis. Additionally, it uses data from five thematic interviews taken in 2018-2020 with the previous or incumbent HELCOM representatives holding various key positions in the organization. This was done to triangulate the data and to add depth of meaning. There was data coherence, as the data from the documents were mainly in agreement with information obtained from the key information interviews. The interviews are referred to as anonymous personal communications as the interviewees were guaranteed anonymity. The interviews were conducted over the phone or Skype and lasted from 1 to $1.5 \mathrm{~h}$. The interviews were thematic discussions with four broad themes taken as a starting point for discussion: the launch of the ecosystem approach by HELCOM, institutional changes required by the approach, problems encountered, and solutions found. The participants were asked to describe the process of how HELCOM started to engage with the ecosystem approach and what kind of problems were encountered in the process, as well as what kind of changes did their solution require in the organization. For the document analysis, key HELCOM documents including the BSAP [3], country implementation reports [9], HELCOM assessment reports [12,42-45] and the database HELCOM explorer [44] were used.

The survey data were collected with the help of the program Qualtrics. The questionnaire was emailed over a period of one month to a list of persons from the HELCOM 
Group on the Implementation of the Ecosystem Approach (GEAR) lists of contacts and observer list and sourced online from the HELCOM meeting portal and publications. These contacts were from all Baltic Sea Coastal states. A reminder was sent a month later. Survey participants were experts who were selected due to their engagement in the studied policy area. The survey included 13 open ended questions that were formulated based on the research design. A total of 29 responses were received. The responses were downloaded from Qualtrics and coded using content analysis into themes that were guided by the transition management framework. In the presentation of the results, we refer to the survey responses by their number from \#1 to \#29.

\section{Results and Discussion}

This section presents the results and discusses them systematically in the seven transition management stages as shown in Table 1.

\subsection{Setting the Scene for Transition Management}

The first step would imply the establishment of a transition team (which would also help to embed the new approach in the local context). Ideally, this step would have occurred simultaneously when planning the BSAP and management options. This kind of a team was not established [13]; however, a specific HELCOM project, guided by HELCOM working groups consisting of national experts was launched in 2003 to coordinate the activity to implement the ecosystem approach [4]. During 2004-2005, the project defined major features of the desired good ecological status including a vision, goals and objectives for the BSAP.

Later, a GEAR working group was established, which some survey respondents (e.g., $\# 16$, \#17, \#24) indicated as a specific team responsible for the implementation of the BSAP. Nonetheless, GEAR was established only after the introduction of the BSAP, not before, as a true transition management team would need to be established. Furthermore, GEAR has a dual role: in principle, it is assigned to implement the BSAP and the ecosystem approach, but in practice, it works to facilitate national marine strategies (personal communication HELCOM representative, June 2019). Therefore, some respondents argued the role and the composition of the GEAR was too narrow (\#18). One respondent questioned the need of a transition team altogether, as the processes for implementing the BSAP, HELCOM recommendations and EU Marine Strategy Framework Directive are so intertwined and overlapping (\#19).

Furthermore, also other working groups and their expert groups take concrete actions both in developing and implementing measures and following their effects (\#17), but they cannot really be considered transition teams as they have many other tasks and they are not designed to manage the transition phase only.

As the BSAP is implemented by the member countries, the national level is important and would also need a transition team of its own. Nonetheless, country implementation reports specified different agencies for each action with little sign of an integrating body. A case study from Sweden, for instance, indicates that the responsibility for implementing different aspects of BSAP was set to various authorities in the public sector, and no processoriented approach to the implementation was applied [30].

\subsection{Exploring Local Dynamics}

No system or actor analysis was conducted (other than ecological system) before the launch of the BSAP [13]. Some respondents (\#17, \#19) mentioned that the HELCOM Holistic Assessments [42] as well as fact sheets produced earlier provided knowledge on the local dynamics, but this was exclusively ecological. Subsequently, some value analyses have been provided by HELCOM [12], but that is of course late compared to the phase of expected implementation. One could assume that the exploration of local dynamics necessitates the involvement of the local level actors, including different stakeholders. Stakeholders were engaged on various occasions since the presentation of a draft BSAP at a 
kick-off stakeholder conference in 2006 (personal communication, HELCOM representative, March 2020; \#19).

Non-governmental organizations were also involved in the development of the BSAP actions [4], but not in the final decision-making on these actions (personal communication, HELCOM representative, March 2020). It is noted that ([30], p. 232), "despite the stakeholder forums initiatives, it is clear that the deep institutional structures of HELCOM (for stakeholder engagement) have not yet changed in accordance with EAM". Additionally, GEAR has a strong bias to environmental matters, and not an approach incorporating social, environmental and economic matters, as it is chaired by the German Environmental Agency and vice chaired by the Ministry of Environment and Food, Denmark [43].

At the country level, states had the freedom to implement the completed BSAP in ways that best suit their particular circumstances. Some countries, such as Sweden, convened a multiagency stakeholder process led by the Swedish environmental protection agency and inked a multiagency agreement for implementation. One theme running through the implementation reports was that implementation was the mandate of several agencies, with various degrees of centralised coordination, mainly through Ministries of the Environment or their equivalents [13].

\subsection{Framing the Transition Challenge}

Initially, the BSAP, particularly with regard to eutrophication which formed the most developed and ambitious part of the plan, was based on a problem framing shared widely within HELCOM actors and scientific community affiliated with HELCOM $[4,46]$. The BSAP demonstrates how actual management alternatives can be defined in terms of the ecosystem approach and what kind of implications this might have for the revised governance system, moving from a sectoral, hot spot based management to holistic and integrated one.

Yet, to be implemented in a societal context, the problem framing should also have wide acceptance among other actors, including administrative bodies at various levels of governance and those who are otherwise engaged with its implementation and whose activities and livelihoods the implementation will affect. It should also include aspects other than ecological. This research found that there was no shared problem framing with some actors, such as farmers. Farmers were one group who bore heavy economic burdens due to the restrictions imposed by the implementation of the BSAP on their activities [47].

The BSAP is an extremely ambitious plan, particularly in terms of nutrient reduction targets, but less clear in its definition of how to reach the targets and, in particular, under what conditions. Thereby, various transition challenges-what was possibly conditioning the implementation of the plan-were not systematically discussed at the HELCOM level when preparing the plan (personal communication, HELCOM representative, March 2020). Furthermore, cost-benefit analyses have been provided and the feasibility of implementation studied $[36,48]$ (respondent \#24) but it is evident that such a broad scale framing of transition challenges before the launch of the plan as the transition management framework presupposes, was not conducted. Later, the problem framing, and shared transition challenges were explored independently in some national implementation programmes (NIP) reports, but not by a common transition team.

\subsection{Envisioning a Sustainable Baltic Sea}

A vision for the sustainable Baltic Sea, guiding the work on the BSAP, was presented in the form of a declaration in the BSAP: "A healthy Baltic Sea environment, with diverse biological components functioning in balance, resulting in good environmental/ecological status and supporting a wide range of sustainable human economic and social activities" [3]. The vision was based on the work of the specific HELCOM project, guided by HELCOM working group experts, and was adopted by the Contracting Parties in 2004 [4]. The vision echoes very much the spirit of the Convention on Biological Diversity, the consensus reached at the United Nations Conference on Environment and Development [25], as well 
as the objective of the EU Water Framework Directive. It also refers to the Convention text: The aim to reach "ecological balance" in the Baltic environment and to the cultural values and ecosystem services important for human societies [2]. Consequently, the vision was based on scientific objectives and its envisioning did not include much deliberation with stakeholders. Subsequently what this means for each country was elaborated in the national implementation plans.

\subsection{Reconnecting Long Term and Short Term}

The BSAP itself is unclear about its relation to the long- and short-term targets. The main goal, reaching the good environmental status by 2021 [3], is as such a long term goal, which is expected to be reached over a very short term. There is one action in the BSAP that clearly points to long-term goals: "develop long-term management plans by 2012 for protecting, monitoring and sustainably managing coast fish species ... " [47]. Additionally, the impetus to constantly revise the plan can be regarded as a tool to reconnect long- and short-term goals, i.e., the update of the plan that is currently going on [48] as well as its future update (\#16). At the HELCOM level, no transition pathways or agendas were drafted; in national implementation plans, this was however included and changes and actions needed to reach the goals set in BSAP were articulated.

Various working groups have different time frames in their work. One respondent noted that, regarding eutrophication, for example, HELCOM group on sustainable agricultural practices (AGRI) has worked with short-term measures within the agricultural sector, whereas HELCOM pressure works with the longer-term follow-up concerning the effect of measures as a whole in the catchment, over decadal timescales (\#17). This is important, as long term studies are important to know the population trends of fish stocks and predator species such as seals, white tailed eagle, salmon and cod [4]. Fish stocks are included in the BSAP under the target of "Favourable conservation status of Baltic Sea biodiversity" [3]. Implementation measures for management of Baltic sea fish stocks are delaying the desired action, as there is one out of six joint actions completed under the BSAP and three out of nine national actions completed with two being set for future target years, further demonstrating the long-term aspect of these actions [47]. These two actions were the improvement in size, age-range for cod and eel [47].

\subsection{Engaging and Anchoring}

HELCOM has a wide list of observers, and stakeholders have various possibilities for engagement (\#19). Nonetheless, there are rather strict conditions for observers, and stakeholders often have the passive role as information receivers, not as true contributors (personal communication HELCOM representative, April 2020) [13,49]. In some working groups NGO representatives work as experts, when they have the required professional expertise (\#18).

In order to encourage engagement and facilitate anchoring, stakeholders should gain a more active role in the renewal of the BSAP, where once again stakeholders are assigned the passive role of observers in meetings [9]. Over the course of the current BSAP, lack of transparency has been an issue that stakeholders have pointed out, along with monitoring of countries' progress and deficient and incoherent national reporting [50]. Under certain HELCOM projects and working groups, connections with local and regional authors have been established (\#18). This helps anchoring, but not in a systematic way. In some NIPs, there was a concerted effort to engage the public whilst this was ignored in others [13].

\subsection{Taking Action}

As noted, the practical implementation of the BSAP is taken at the country level. Yet, HELCOM is responsible for monitoring and updating, so action is expected also at the HELCOM level. The BSAP is discussed at meetings, but mainly from the monitoring point of view, implying an outside position rather than active engagement (personal communication, HELCOM representative, June 2019). HELCOM has not provided platforms 
for learning and sharing experiences between implementing authorities; this could, for instance, have been one step to take in order to facilitate implementation and mutual learning. It would also help to incorporate feedback loops on all possible, known and unknown outcomes, and to cope with time lags. True, countries have taken activities obviously inspired by the BSAP and its targets. For instance, in Finland some piloting activities have been taken, including experimenting with the spreading of gypsum on the field parcels to prevent nutrient leakage which later developed into a broader measure (\#19). Analysis of country reports also shows that there was some evidence of sharing of experiences by cities, but this was not systemic [13].

\subsection{Summary of Results}

The preceding sections detailed the results of applying the transition management framework to the case study of HELCOM. Table 2 further summarizes the differences between the current policy framework at HELCOM and the transition policy framework. As discussed, the current policy framework is myopic with a short-term goal of 2021, whilst transition management encompasses policies that are long-term and innovative.

Table 2. The Helsinki Commission (HELCOM) in current vs. transition management Baltic Sea Action Plan (BSAP) approach.

\begin{tabular}{cc}
\hline HELCOM-Current BSAP Approach (Is) & HELCOM-Transition Management BSAP Approach (Should Be) \\
\hline Short time scale (5-10 years) & Long time scale (25-50 years) \\
\hline Sectoral Approach & Integrated approach \\
\hline $\begin{array}{c}\text { Limited number of actors making decisions, hierarchical } \\
\text { and closed }\end{array}$ & Multi actor decision making, participatory and inclusive \\
\hline One scale level & Multi level \\
\hline Incremental change & Innovative change \\
\hline Usual steering tools & Feedback loops \\
\hline Linear mechanisms & Adaptive, process, design focused \\
\hline Reactive, planning, solution focus
\end{tabular}

\section{Conclusions}

The transition management approach applied in this study is a useful tool for understanding change and actions needed to facilitate the change process in institutions for long-term transformation and to ensure the meeting of governance requirements necessitated by the ecosystem approach. HELCOM effected changes to incorporate the implementation of the ecosystem approach as stipulated in the BSAP. The analysis indicates that the emergence of the ecosystem approach influenced HELCOM mostly in terms of problem framing and envisioning. The BSAP shows clearly how objectives and suggested remedies are being defined and what kind of a common vision can be used to frame the objectives. Regarding transition management, it seems to be the case that HEL$\mathrm{COM}$ is entrenched in its history and has strong path dependency in terms of its potential for change. The internal structure of HELCOM has remained almost unaltered and no major institutional changes have been made to implement the BSAP. Although GEAR was set up for the implementation of the ecosystem approach, its position on the HELCOM governing structure should be revisited. It should encompass the entire HELCOM as an overarching integrating circle, rather than a branch on the structure. In addition, national implementation with path dependencies and lack of a systematic and focused grip in each country seems to form a further obstacle in managing the transition. Consequently, it can be assumed that newer environmental organizations that inherit the same type of legacy and path dependency could be more flexible and open to transition. 
Accelerated implementation of the ecosystem approach will occur if the update of the BSAP (BSAP 2.0) sets the conditions for a more integrated science; science that articulates economic consequences of various policy options, that incorporates and responds to feedback loops and cumulative ecological conditions. BSAP 2.0 must stipulate better leadership arrangements that can guide formal rules of engagement among and across sectors such as land use, fisheries and agriculture. Facilitated engagement of actors in these sectors on the transitions required for the implementation of the ecosystem approach has the potential to reveal new information and can break prevailing practices. As such, the overarching governance paradigm of the BSAP needs to shift for the ecosystem approach to become embedded in ongoing practice. Going forward to BSAP 2.0, to bring this transition process into practice the tolerance, space and culture of innovation needs to be expanded and diffused to the operational levels. Key transition actors should be trained to deal with the transition processes and a transition innovation team should facilitate this transition. Furthermore, successful implementation of the ecosystem approach as stipulated in BSAP can only occur through an improved common understanding of the ecosystem approach by actors and institutions that is delivered through dialogue and training.

In summary, the overarching philosophy of transition management is useful to examine the institutional changes required by international organizations for the implementation of the ecosystem approach. The transition management philosophy is captured by key principles that have been used to describe the governing of wicked problems such as eutrophication of the Baltic Sea: multiple and conflicting values, embracing change and complexity, flexible, uncertain and multilevel governance. The key principles from transition management that can be translated into a governance strategy to govern institutional changes in organizations such as HELCOM for implementation of the ecosystem approach are as follows:

- Stakeholder participation is necessary for new framing of transitions such as from sectoral policies to the ecosystem approach. It also helps in developing support and solutions to manage the transitions.

- Hierarchical steering mechanisms from outside the system are not effective. Steering from inside by a transition management team is better for adapting structures, actors and perspectives to uncertain and complex changes.

- Goals and objectives should be flexible and adaptable at the ecosystem level. The complexity of an ecosystem such as the Baltic Sea is at odds with the formulation of fixed objectives and plans. The dynamics of an international organization such as HELCOM will change whilst being directed under ecosystem management objectives, and as the organization is changing, so should be objectives as this new information is fed back into the system.

- Creating the conditions for transition agents to innovate alternative regimes is crucial for successful transition management. In the case of international organizations this can be creating safe spaces for meetings and dedicating time, energy and resources to them.

- Managing wicked problems in a complex system means using periods of stability as well as periods of rapid change. Periods of relative inertia such as these moments during the COVID-19 lockdown can be used as opportunities to direct the system into a desirable direction, e.g., planning for BSAP 2.0.

- The timing of transition management is crucial. Whilst immediate intervention is needed in crisis situations, such as a eutrophication event, long-term planning is critical to achieve good environmental outcomes. Long-term thinking should guide short-term policy to effect institutional changes that are needed to implement the ecosystem approach.

- Scenario planning can guide forecasting of future events for long-term planning.

In conclusion, the transition management process is a useful tool to propel institutional changes that are needed by international environmental organizations to incorporate the ecosystem approach and is most useful at the early stages that may require breakthroughs 
of system deadlocks. Further research in this area can explore the transition management approach at other phases in the policy making processes.

Author Contributions: This article was conceptualized by S.J. and N.T. and outline drafted by S.J. Literature review, methods and results and discussion written by both N.T. and S.J. Coding and data analysis done by both S.J. and N.T. Both authors have read and agreed to the published version of the manuscript.

Funding: This research received academy of Finland SeaHer funding, grant number 315715. The authors also wish to acknowledge support from the 'Sea' profiling area of Åbo Akademi University.

Institutional Review Board Statement: Not applicable.

Informed Consent Statement: Not applicable.

Data Availability Statement: Data is stored centrally at Åbo Akademi University.

Conflicts of Interest: The authors declare no conflict of interest.

\section{References}

1. Söderström, S.; Kristine, K. The Ecosystem approach to management in marine environmental governance: Institutional interplay in the Baltic Sea Region. Environ. Policy Gov. 2017, 27, 619-631. [CrossRef]

2. HELCOM. Convention on the Protection of the Marine Environment of the Baltic Sea Area; HELCOM: Helsinki, Finland, 1974.

3. HELCOM. HELCOM Baltic Sea Action Plan. In Proceedings of the HELCOM Ministerial Meeting, Krakow, Poland, 15 November 2007.

4. Backer, H.; Leppänen, J.-M. The HELCOM system of a vision, strategic goals and ecological objectives: Implementing an ecosystem approach to the management of human activities in the Baltic Sea. Aquat. Conserv. Mar. Freshw. Ecosyst. 2008, 18, 321-334. [CrossRef]

5. Elmgren, R.; Blenckner, T.; Andersson, A. Baltic Sea management: Successes and failures. Ambio 2015, 44, 335-344. [CrossRef]

6. Jetoo, S.; Joas, M. Governance of Transboundary Water Commissions Comparison of Operationalizing the Ecosystem Ap-proach in the North American Great Lakes and the Baltic Sea. In Lake Governance; CRC Press: Boca Raton, FL, USA, 2018 ; pp. 111-129.

7. Gilek, M.; Karlsson, M.; Udovyk, O.; Linke, S. Science and policy in the governance of Europe's marine environment: The impact of Europeanization, regionalization and the ecosystem approach to management. In Governing Europe's Marine Environment; Routledge: London, UK, 2016; Volume 20, pp. 157-176.

8. Grönholm, S.; Jetoo, S. The potential to foster governance learning in the Baltic Sea Region: Network governance of the European Union Strategy for the Baltic Sea Region. Environ. Policy Gov. 2019, 29, 435-445. [CrossRef]

9. HELCOM. National Programmes. Available online: https://helcom.fi/baltic-sea-action-plan/follow-up-of-helcom-agreements/ national-programmes / (accessed on 9 June 2020).

10. Patterson, J.; Schulz, K.; Vervoort, J.; van der Hel, S.; Widerberg, O.; Adler, C.; Hurlbert, M.; Anderton, K.; Sethi, M.; Barau, A.S. Exploring the governance and politics of transformations towards sustainability. Environ. Innov. Soc. Transit. 2017, $24,1-16$. [CrossRef]

11. Valman, M. Three Faces of HELCOM Institution, Organization, Policy Producer. Ph.D. Thesis, Department of Political Science, Stockholm University, Stockholm, Sweden, 2014.

12. HELCOM. Implementation of the Baltic Sea Action Plan 2018: Three years left to meet good environmental status. Baltic Marine Environment Protection Commission. In Proceedings of the Brussels Ministerial Meeting HELCOM, Brussels, Belgium, 6 March 2018.

13. Jetoo, S. An Assessment of the Baltic Sea Action Plan (BSAP) Using the OECD Principles on Water Govern-ance. Sustainability 2019, 11, 3405. [CrossRef]

14. Bos, J.; Brown, R. Governance experimentation and factors of success in socio-technical transitions in the urban water sector. Technol. Forecast. Soc. Chang. 2012, 79, 1340-1353. [CrossRef]

15. Kelly, C.; Ellis, G.; Flannery, W. Conceptualizing change in marine governance: Learning from transition management. Mar. Policy. 2018, 95, 24-35. [CrossRef]

16. Rotmans, J.; Kemp, R.; Asselt, M.V. More evolution than revolution: Transition management in public policy. Foresight-J. Future Stud. Strateg. Think. Policy. 2001, 3, 15-31. [CrossRef]

17. Gissi, E.; Fraschetti, S.; Micheli, F. Incorporating change in marine spatial planning: A review. Environ. Sci. Policy 2019, 92, 191-200. [CrossRef]

18. Gee, K.; Blazauskas, N.; Dahl, K.; Göke, C.; Hassler, B.; Kannen, A.; Leposa, N.; Morf, A.; Strand, H.; Weig, B.; et al. Can tools contribute to integration in MSP? A comparative review of selected tools and approaches. Ocean Coast. Manag. 2019, 179, 104834. [CrossRef]

19. Grin, J.; Rotmans, J.; Schot, J. Transitions to Sustainable Development: New Directions in the Study of Long TermTransformative Change, 1st ed.; Taylor and Francis Ltd.: New York, NY, USA, 2010. 
20. Scarff, G.; Fitzsimmons, C.; Gray, T. The new mode of marine planning in the UK: Aspirations and challenges. Mar. Policy 2014, 51, 96-102. [CrossRef]

21. Smith, A.; Kern, F. The transitions storyline in Dutch environmental policy. Environ. Politics 2009, 18, 78-98. [CrossRef]

22. Verbong, G.; Loorbach, D. (Eds.) Governing the Energy Transition: Reality, Illusion or Necessity? Routledge: London, UK, 2012.

23. Roorda, C.; Wittmayer, J.; Henneman, P.; van Steenbergen, F.; Frantzeskaki, N.; Loorbach, D. Transition Management in the Urban Context: Guidance Manual; DRIFT, Erasmus University Rotterdam: Rotterdam, The Netherlands, 2014.

24. Loorbach, D. Transition Management for Sustainable Development: A Prescriptive, Complexity-Based Governance Framework. Governance 2010, 23, 161-183. [CrossRef]

25. United Nations. Ecosystem Approach; Convention on Biological Diversity (CBD): Montreal, QC, Canada, 1992.

26. UNEP. COP IV Decision IV/1. Unep/Cbd/Cop/4/27. In Proceedings of the Fourth Meeting of the Conference of the Parties to the Convention on Biological Diversity, Bratislava, Slovakia, 4-15 May 1998.

27. Maltby, E. Ecosystem approach: From principle to practice. In Proceedings of the Ecosystem Service and Sustainable Watershed Management in North China International Conference, Beijing, China, 23-25 August 2000; pp. 205-224.

28. Grumbine, R.E. What Is Ecosystem Management? Conserv. Biol. 1994, 8, 27-38. [CrossRef]

29. HELCOM, OSPAR. In Proceedings of the Declaration of the First Joint Ministerial Meeting of the Helsinki and OSPAR Commissions, Bremen, Germany, 25-26 June 2003. Available online: https:/ /www.ospar.org/site/assets/files/36552/jmm_2003_joint_ ministerial_declaration.pdf (accessed on 5 February 2020).

30. Hassler, B.; Boström, M.; Grönholm, S. Towards an Ecosystem Approach to Management in Regional Marine Governance? The Baltic Sea Context. J. Environ. Policy Plan. 2013, 15, 225-245. [CrossRef]

31. Nielsen, H.Ø.; Frederiksen, P.; Saarikoski, H.; Rytkönen, A.-M.; Pedersen, A.B. How different institutional arrangements promote integrated river basin management. Evidence from the Baltic Sea Region. Land Use Policy 2013, 30, 437-445. [CrossRef]

32. Hammer, M. The Ecosystem Management Approach. Implications for Marine Governance. Governing Europe's Marine EnviRonment. Europeanization of Regional Seas or Regionalization of EU Policies. 2015. Available online: https: / /www.diva-portal. org/smash/get/diva2:786870/FULLTEXT01.pdf (accessed on 5 February 2020).

33. Hegland, T.J.; Raakjær, J.; van Tatenhove, J. Implementing ecosystem-based marine management as a process of regionalisation: Some lessons from the Baltic Sea. Ocean Coast. Manag. 2015, 117, 14-22. [CrossRef]

34. Van Soma, K.; van Tatenhove, J.; Leeuwen, J. Marine Governance in a European context: Regionalization, integration and cooperation for ecosystem-based management. Ocean Coast. Manag. 2015, 117, 4-13. [CrossRef]

35. Söderström, S. Institutional Interplay in Governing the Baltic Sea Environment: The Role of IMO, EU, HELCOM and Classification Societies as Quasi-governmental Organizations. 2017. Available online: http://www.diva-portal.org/smash/record.jsf? pid=diva2\%3A1076212\&dswid=3321 (accessed on 3 May 2020).

36. Elofsson, K. Cost-effectiveness of the Baltic Sea Action Plan. Mar. Policy 2010, 34, 1043-1050. [CrossRef]

37. Tynkkynen, N.; Schönach, P.; Pihlajamäki, M.; Nechiporuk, D. The governance of the mitigation of the Baltic Sea eutrophication: Exploring the challenges of the formal governing system. Ambio 2014, 43, 105-114. [CrossRef]

38. Wulff, F.; Humborg, C.; Andersen, H.E.; Blicher-Mathiesen, G.; Czajkowski, M.; Elofsson, K.; Fonnesbech-Wulff, A.; Hasler, B.; Hong, B.; Jansons, V.; et al. Reduction of Baltic Sea Nutrient Inputs and Allocation of Abatement Costs Within the Baltic Sea Catchment. Ambio 2014, 43, 11-25. [CrossRef]

39. Ollikainen, M.; Hasler, B.; Elofsson, K.; Iho, A.; Andersen, H.E.; Czajkowski, M.; Peterson, K. Toward the Baltic Sea Socio-economic Action Plan. Ambio 2019, 48, 1377-1388. [CrossRef]

40. Gadgil, M.; Olsson, P.; Berkes, F.; Folke, C. Exploring the role of local ecological knowledge in ecosystem management: Three case studies. Navig. Soc. Ecol. Syst. 2001, 189, 209. [CrossRef]

41. Schultz, L.; Folke, C.; Österblom, H.; Olsson, P. Adaptive governance, ecosystem management, and natural capital. Proc. Natl. Acad. Sci. USA 2015, 112, 7369-7374. [CrossRef] [PubMed]

42. HELCOM. Ecosystem health of the Baltic Sea 2003-2007. In HELCOM Initial Holistic Assessment; HELCOM: Helsinki, Finland, 2017; p. 122.

43. HELCOM. HELCOM Website. Helcom at Work. 2019. Available online: https://helcom.fi/helcom-at-work/groups/gear/ (accessed on 7 February 2020).

44. HELCOM. Implementation of the BSAP. 2018 and HELCOM Explorer. Available online: http://maps.helcom.fi/website/ HELCOMexplorer/ (accessed on 4 May 2020).

45. HELCOM BSAP Update HELCOM Website. 2020. Available online: https://helcom.fi/baltic-sea-action-plan/bsap-update-2021/ (accessed on 4 May 2020).

46. Pihlajamäki, M.; Tynkkynen, N. The Challenge of Bridging Science and Policy in the Baltic Sea Eutrophication Governance in Finland: The perspective of Science. Ambio 2011, 40, 191-199. [CrossRef] [PubMed]

47. Was, A.; Zawalinska, K.; Brizt, W. Impact of "greening" the Common Agricultural Policy on sustainability of European agriculture: From perspective of the Baltic Sea countries. J. Agribus. Rural. Dev. 2014, 34, 191-212.

48. Hyytiäinen, K.; Blyh, K.; Hasler, B.; Ahlvik, L.; Ahtiainen, H.; Artell, J.; Ericsdotter, S. Environmental Economic Research as a Tool in the Protection of the Baltic Sea-Costs and Benefits of Reducing Eutrophication; Nordic Council of Ministers: Copenhagen, Denmark, 2014. 
49. Dreyer, M.; Selke, P.; Jönsson, A.-M.; Boström, M. Structures and Processes of Stakeholder and Public Communication on Baltic Sea Environmental Risks; RISKGOV Report, Delivery Number 10; Södertörn University: Huddinge, Sweden, 2011.

50. Littfass, D. HELCOM Expert Interview: Ottilia Thoreson on the Baltic Sea, HELCOM Stakeholders and the BSAP Update. Available online: https://helcom.fi/helcom-expert-interview-ottilia-thoresen-on-the-baltic-sea-helcom-stakeholders-and-thebsap-update/ (accessed on 28 April 2020). 